\title{
De winter ECG pattern with acute thrombotic occlusion of diagonal while lad is patent
}

\author{
Volume 7 Issue I - 2016
}

\section{Summary}

De Winter ECG pattern can present with thrombus occlusion of Diagonal branch while LAD is patent.

\section{Presentation}

53years old patient known with hypertension, not diabetic, presented with 3 hours continuous typical chest pain at rest, after emotional stress. His hemodynamics were stable, BP was 170/100, Heart rate was $60 \mathrm{bpm}$ (on bisoprolol 10mg daily), clinical examination was normal.

\section{Initial findings}

ECG (Figure 1a) showed upsloping ST depression at the J point from Lead V3 to V6 that continued into tall, positive symmetrical T waves, with narrow QRS complex) (De Winter pattern described in new england journal of medicine 359;19 november 6, 2008). Bedside Echocardiography showed normal LV systolic function with akinitic antero-lateral wall.

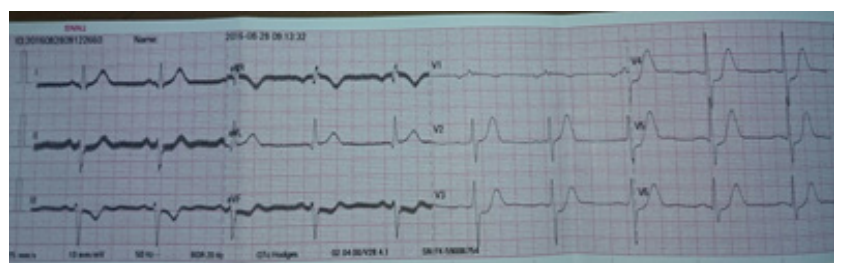

Figure IA

\section{Treatment}

Patient transfered to Cardiac Catheterization Laboratory, coronary angiography showed atherosclerotic coronaries but without significant lesions, especially LAD that was patent with TIMI 3 flow (Figure 15). Re-evaluation of the Angiography showed a small stump that can be for an occluded 1st diagonal (Figure 2a), at that level the LAD has a non-significant lesion.

Although it was not convenient, but started trying to wire that diagonal based on:
a. The resting chest pain.
b. ECG changes.
c. Echocardiographic Data.

After crossing with the PTCA wire, a minimal flow started to appear in the diagonal branch (Figure 6), then LAD was wired, then a $2 \times 15 \mathrm{~mm}$ Balloon was used to pre-dilate (Figure 7,8), a big diagonal branch appeared with proximal thrombotic tight lesion (Figure 9), the diagonal angle to LAD was about 90 degree (Figure 10), so provisional stenting done to diagonal from its ostium with $3 \times 20 \mathrm{~mm}$ PROMUS ELEMENT PLUS DES (Figure 11,12), with good final result (Figures 13\&14).

\begin{abstract}
Ahmed Said Saad
Interventional cardiologist at Shebin Elkoum Teaching Hospital, Egypt

Correspondence: Ahmed Said Saad, Interventional cardiologist at Shebin Elkoum Teaching Hospital, Egypt, Email cardiologist82@hotmail.com
\end{abstract}

Received: September 0I, 2016 | Published: November 08, 2016

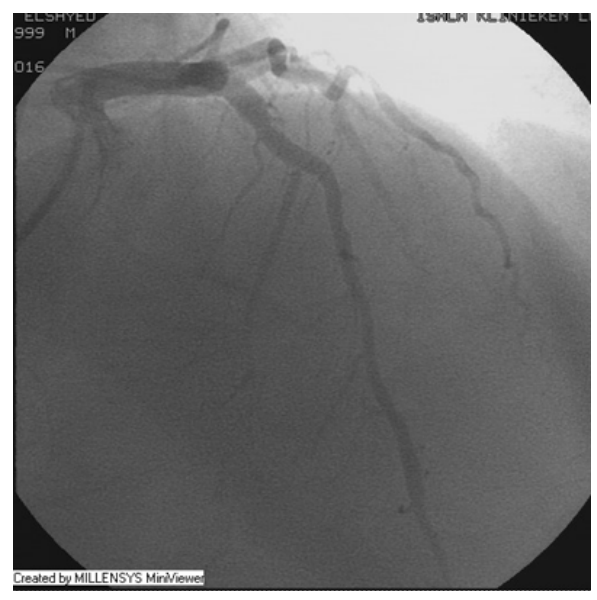

Figure I

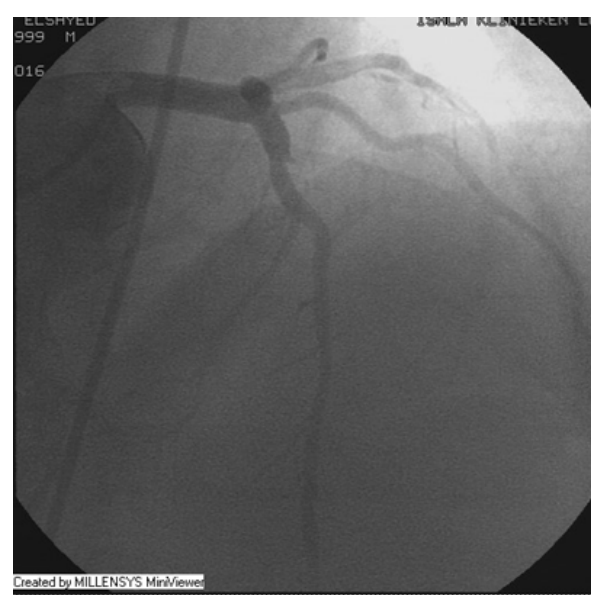

Figure 2 


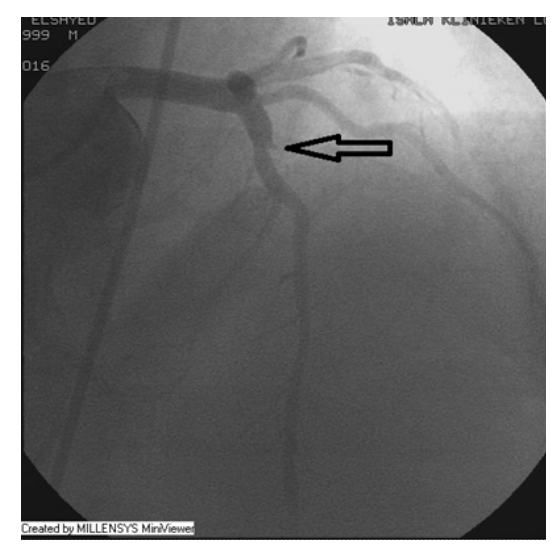

Figure 2A

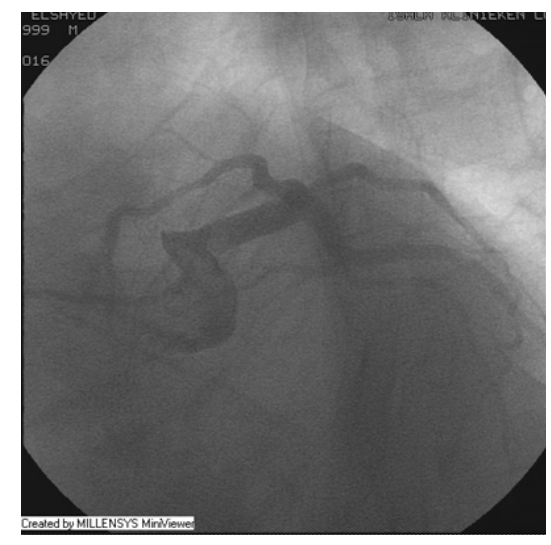

Figure 3

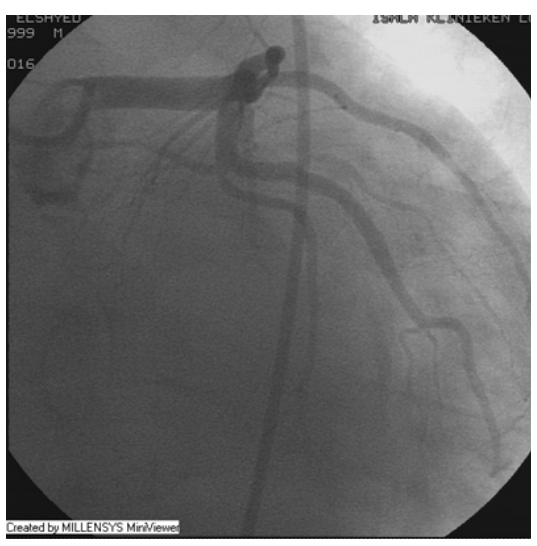

Figure 4

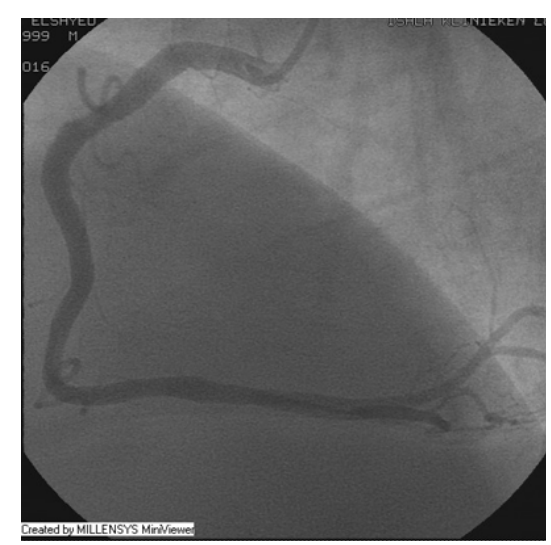

Figure 5

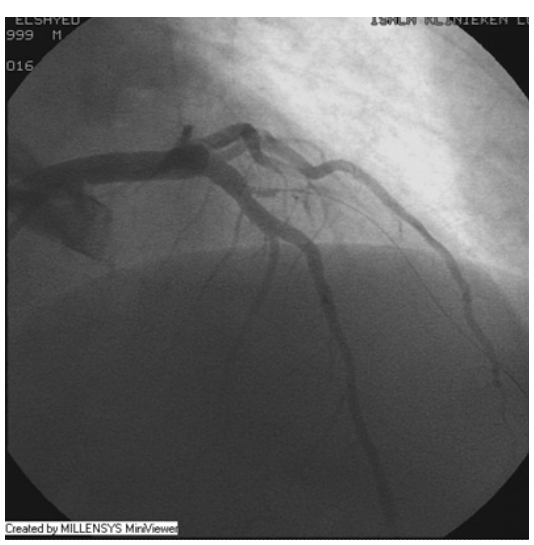

Figure 6

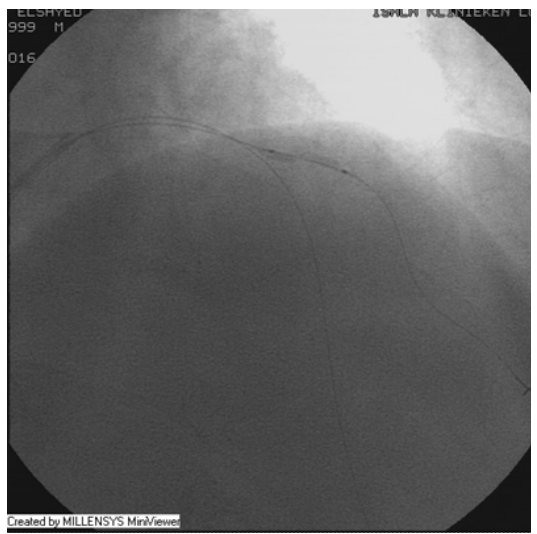

Figure 7

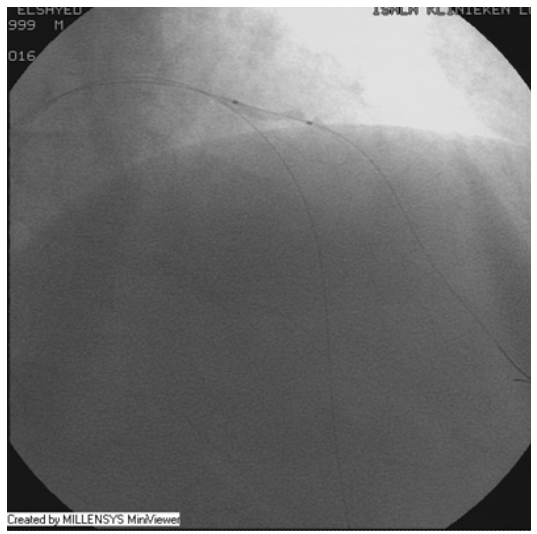

Figure 8

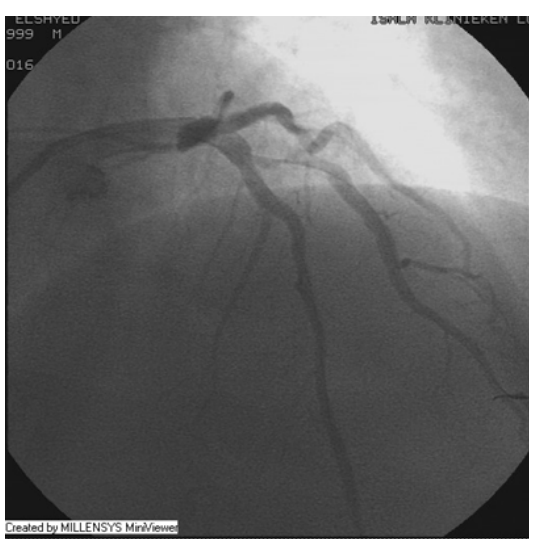

Figure 9

Citation: Saad AS. De winter ECG pattern with acute thrombotic occlusion of diagonal while lad is patent.J Cardiol Curr Res. 20 I6;7(I): I-6. DOI: 10.15406/jccr.2016.07.00233 


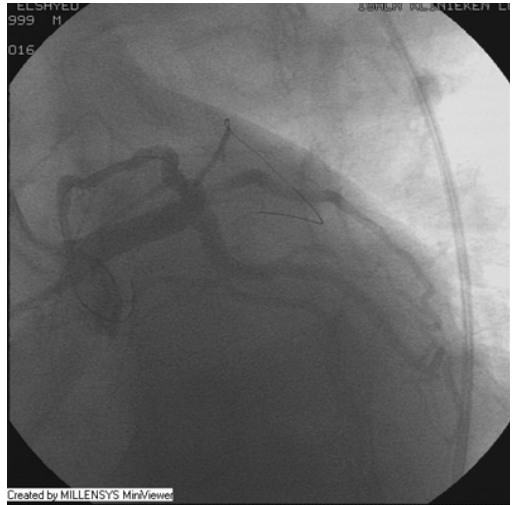

Figure 10

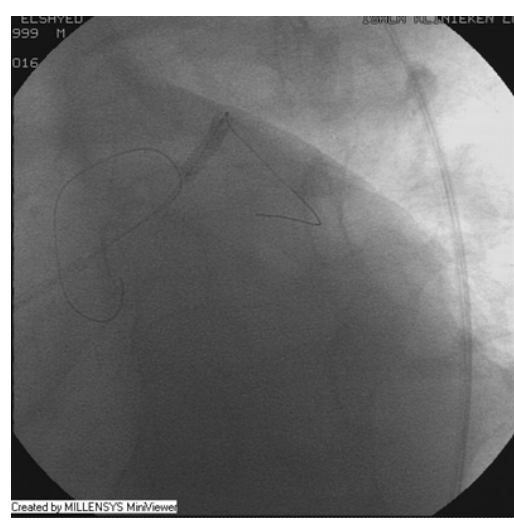

Figure I I

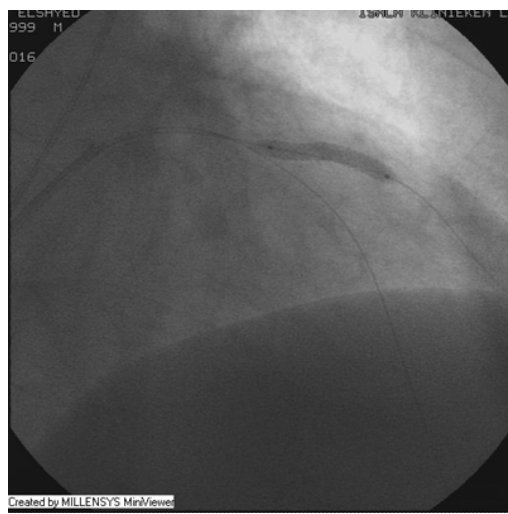

Figure 12

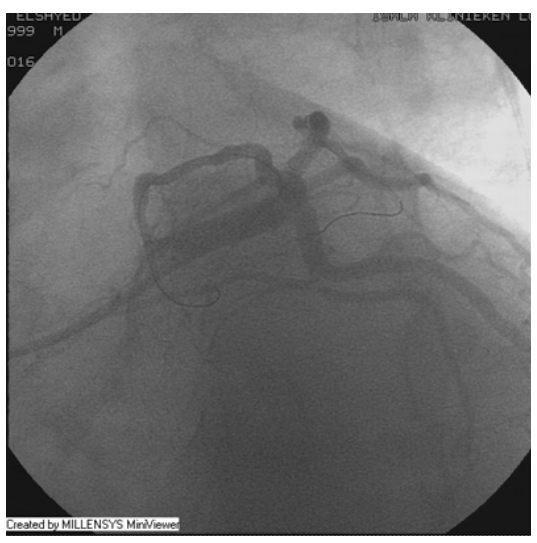

Figure 13

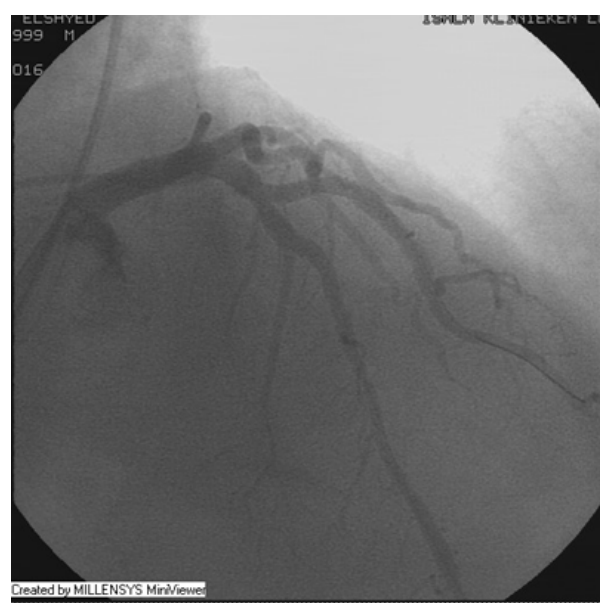

Figure 14

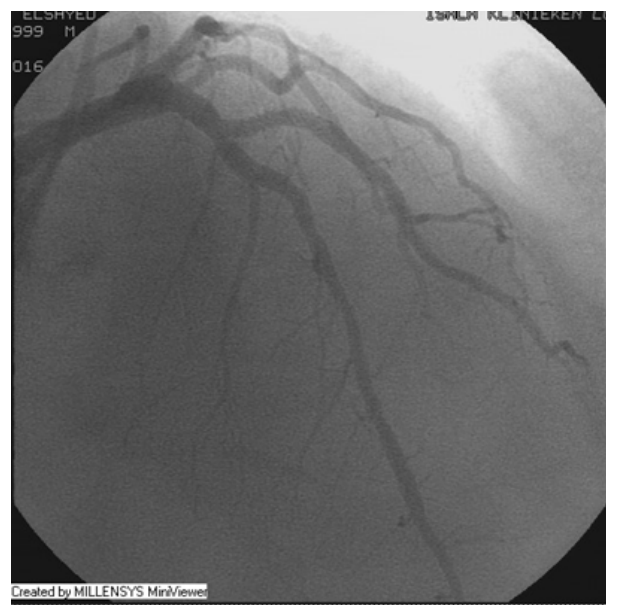

Figure I5

\section{Discussion}

The ECG Sign of Proximal LAD Occlusion, that was described by Robbert J. de Winter et al. in 2008, was discovered in this patient, The ST depression was from V3 to V6, unlike De Winter pattern which was from V1 to V6, also his LAD was patent with TIMI 3 flow, while the occlusion was in a big diagonal that could be missed because of the ostial position of the occluding thrombus. Explanation of these changes instead of the ST segment elevation is still not clear, although De Winter et al. theoretically assumed an anatomical variant of the Purkinje fibers, with endocardial conduction delay, or the absence of ST elevation may be related to the lack of activation of sarcolemmal ATPsensitive potassium (KATP) channels by ischemic ATP depletion. The occlusion of the diagonal can explain the ST depression in V3 to V6 (not in V1 and V2) that was described by De Winter as specific for LAD (V1 to V6).

\section{Acknowledgments}

None.

\section{Conflicts of interest}

Author declares there is no conflicts opf interest.

\section{Funding}

None. 